\title{
Role of Mastoid Pneumatization in Temporal Bone Fractures
}

\author{
A. Ilea, A. Butnaru, S.A. Sfrângeu, M. Hedeşiu, C.M. Dudescu, P. Berce, H. Chezan, L. Hurubeanu, V.E. Trombiţaş,
} R.S. Câmpian, and S. Albu

\begin{abstract}
BACKGROUND AND PURPOSE: The mastoid portion of the temporal bone has multiple functional roles in the organism, including regulation of pressure in the middle ear and protection of the inner ear. We investigated whether mastoid pneumatization plays a role in the protection of vital structures in the temporal bone during direct lateral trauma.
\end{abstract}

MATERIAL AND METHODS: The study was performed on 20 human temporal bones isolated from cadavers. In the study group formed by 10 temporal bone samples, mastoid cells were removed and the resulting neocavities were filled. The mastoids were maintained intact in the control group. All samples were impacted at the same speed and kinetic energy. The resultant temporal bone fractures were evaluated by CT.

RESULTS: Temporal squama fractures were 2.88 times more frequent, and mastoid fractures were 2.76 times more frequent in the study group. Facial nerve canal fractures were 6 times more frequent in the study group and involved all the segments of the facial nerve. Carotid canal fractures and jugular foramen fractures were 2.33 and 2.5 times, respectively, more frequent in the study group.

CONCLUSIONS: The mastoid portion of the temporal bone plays a role in the absorption and dispersion of kinetic energy during direct lateral trauma to the temporal bone, reducing the incidence of fracture in the setting of direct trauma.

$\mathbf{T}$ he mastoid portion of the temporal bone has a pneumatic structure similar to that of the paranasal sinuses. While pneumatized paranasal structures have developed phylogenetically be-

Received September 25, 2013; accepted after revision November 25.

From the Faculty of Dental Medicine, Department of Oral Rehabilitation, Oral Health and Dental Office Management (R.S.C., I.A.); Faculty of Medicine, Department of Radiology (A.B., S.A.S.); Faculty of Dental Medicine, Department of Dental Radiology (M.H.) Faculty of Dental Medicine, Department of Cervicofacial and Ear, Nose, and Throat Surgery (S.A., V.E.T.); and Faculty of Dental Medicine, Department of Oral and Maxillofacial Surgery (L.H.), "Iuliu Haţieganu" University of Medicine and Pharmacy ClujNapoca, Romania; and Faculty of Machine Building, Department of Manufacturing Engineering (P.B., H.C.) and Faculty of Mechanics, Department of Mechanical Engineering (C.M.D.), Technical University Cluj-Napoca, Romania.

Author Contributions: Aranka llea and Radu S. Câmpian: 1) substantial contributions to conception and design, acquisition of data, analysis and interpretation of data, 2) drafting the article and revising it critically for important intellectual content, 3) final approval of the version to be published; Anca Butnaru and Silviu A. Sfrângeu: 1) acquisition of data, analysis and interpretation of data; 2) revising the article critically for important intellectual content; 3) final approval of the version to be published; Mihaela Hedeșiu: 1) acquisition of data, analysis and interpretation of data; 2) revising the article critically for important intellectual content; 3) final approval of the version to be published; Cristian M. Dudescu: 1) substantial contributions to conception and design, acquisition of data, analysis and interpretation of data; 2 ) revising the article critically for important intellectual content; 3 ) final approval of the version to be published; Petru Berce and Horea Chezan: 1) acquisition of data; 2) revising the article critically for important intellectual content; 3) final approval of the version to be published; Lucia Hurubeanu: 1) substantial contributions to design; 2) revising the article critically for important intellectual content; 3) final approval of the version to be published; Silviu Albu and Veronica E. Trombițas 1) substantial contributions to conception and design, acquisition of data, analysis and interpretation of data; 2) drafting the article and revising it critically for important intellectual content; 3) final approval of the version to be published. cause of multiple functional needs, ${ }^{1}$ however, the functional roles of the mastoid are discussed less in the literature. Hill and Richtsmeier ${ }^{2}$ designated pneumatic cells in the temporal bone as enigmatic structures. They showed that temporal bone pneumatization has diminished during the evolution of the human species, but little is known about the cause or effect of this process. ${ }^{2}$ Mastoid cells are completely formed around 10 years of age and reach maturity between 15 and 20 years of age. ${ }^{3,4}$ In the adult, there are no differences in the size of the mastoid between men and women. ${ }^{5}$ Also, Han et $\mathrm{al}^{6}$ found no statistically significant differences in mastoid pneumatization between the right and left side. The size of mastoid cells is not only determined genetically, but environmental factors are also involved. The volume of mastoid cells depends on the degree of impairment of the middle ear during childhood, such as recurrent acute otitis media or otitis media with effusion. ${ }^{7}$ Turgut and $\operatorname{Tos}^{8}$ found mastoid length to be significantly shorter in specimens with pathologic eardrum and middle ear adhesions. Pneumatization was also decreased in spec-

This work was supported by the POSDRU project 88/1.5/S/78702.

Please address correspondence to Aranka llea, MD, Victor Babeş, No 15, First Floor, Cluj-Napoca, Romania; e-mail: cseh.aranka@umfcluj.ro

- Indicates open access to non-subscribers at www.ajnr.org

http://dx.doi.org/10.3174/ajnr.A3887 


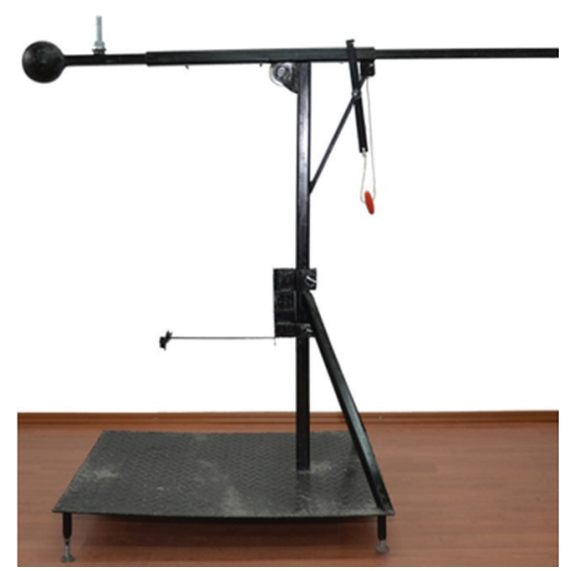

FIG 1. The impacting system.

imens with a short length of the mastoid process. However, it is not clear whether reduced temporal bone pneumatization is the effect of middle ear infections or their cause.

Kellman and Schmidt ${ }^{1}$ demonstrated the role of the paranasal sinuses in the protection of the eyeball. They showed that a direct blow on the eyeball causes fracture of the orbit floor, while the eyeball remains intact. In contrast, if the paranasal sinuses are filled with bone cement, direct eye trauma causes rupture of the eyeball, without orbit fractures. ${ }^{1}$

We hypothesize that mastoid pneumatization plays a role similar to that of the paranasal sinuses: to protect vital structures such as the facial nerve, blood vessels, and central nervous tissue, by dissipating energy.

\section{MATERIALS AND METHODS Study Samples}

The study was performed on isolated temporal bones collected from human cadavers. After removal, the temporal bones were treated with formalin for preservation. The study was approved by the Ethics Board of the "Iuliu Haţieganu" University of Medicine and Pharmacy, Cluj-Napoca, No. 250/22. 02. 2011.

The study included 20 temporal bone samples that were randomly assigned to 2 groups. The study group consisted of 10 temporal bone samples (S1-S10) from which mastoid cells were removed by an external approach. The resulting cavity was filled with a mixture of calcium carbonate, white gypsum (semihydrated calcium sulfate), and hydroxyapatite in a proportion of 10:10:1. The other 10 temporal bone samples had their mastoid cells intact and represented the control group (M1-M10).

\section{The Impacting System}

Each of the 20 temporal bone samples was fixed on a metal support with an irreversible elastic material (sodium alginate, an irreversible hydrocolloid impression material). All samples were impacted at a mean speed of $3.35 \pm 0.013 \mathrm{~m} / \mathrm{s}$ and a mean kinetic energy of $50.50 \pm 0.39 \mathrm{~J}$ generated by a rigid arm pendulum (Fig 1). There were no statistically significant differences in the impacting speed or kinetic energy between the 2 groups $(P=.17)$. The weight of the impacting pendulum was $9 \mathrm{~kg}$, the radius of the bob was $60 \mathrm{~mm}$, and the length of the pendulum arm was $62 \mathrm{~cm}$.

The impact to the temporal bone samples was performed at

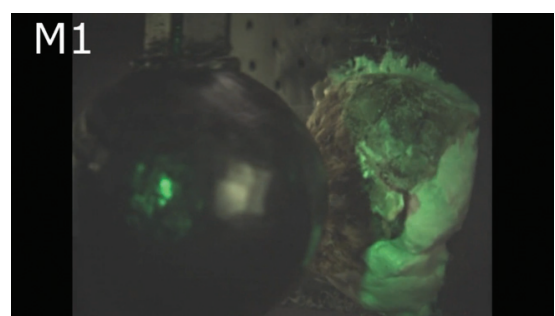

FIG 2. Impaction of sample Ml of the control group.

the same point on the exocranial surface of the temporal bone, in the region of the junction of the mastoid with the temporal squama, by using laser light guidance (Fig 2 or see impaction at the following link: https://vimeo.com/73047373).

\section{Imaging Examinations}

All temporal bone samples were examined with CT, and images were analyzed by 3 radiologists. For the evaluation of fracture lines, the spiral acquisition mode with 350 -mAs values was used (automatic modulation); $120 \mathrm{kV}$; collimation, 0.65; pitch, 0.8; reconstructed sections, $0.62-0.65 \mathrm{~mm}$, with bone filter, by using a multidetector device with 64 detector rows (Optima CT660 128SL with ASiR; GE Healthcare, Milwaukee, Wisconsin).

CT images were evaluated by axial acquisitions of the impacted samples in the anatomic position of the right temporal bone. Temporal bone fractures were evaluated in the axial plane and in coronal and sagittal multiplanar reconstructions and in a $3 \mathrm{D}$ bone reconstruction volume-rendering technique.

Fractures were classified according to the anatomic segment of the temporal bone and the horizontal and vertical planes. The styloid process was not assessed because it was absent in some anatomic samples. Horizontal or transverse fractures were defined in the horizontal plane for the squamous and mastoid parts and as fractures coursing perpendicular to the petrous ridge for the petrous part. Vertical or longitudinal fractures were defined in the vertical plane for squamous and mastoid parts and as fractures running parallel to the petrous ridge for the petrous part. Oblique fractures were defined as fractures crossing the petrotympanic fissure, and coursing between the horizontal and vertical planes for the squamous and mastoid parts. The involvement of vital structures was defined by the presence of fracture lines on at least 1 of the walls surrounding that structure, regardless of the fracture plane. Comminuted fractures had multiple horizontal, longitudinal, and/or transverse components of the same parts of the temporal bone. Temporal bone fractures were defined as petrous fractures when the fracture lines were extending to the otic capsule or/and petrous apex. Nonpetrous fractures were defined as fractures that did not involve the otic capsule or petrous apex. ${ }^{9}$

For evaluation of temporal bone pneumatization, CT was performed in axial sections by using the spiral acquisition mode with values of $350 \mathrm{mAs}$ (automatic modulation), $120 \mathrm{kV}$, with a 6-mm thickness of acquired and reconstructed sections, pitch of 0.5 , by using a 20-row multidetector device, with an inner ear filter.

Temporal bone pneumatization was assessed after impaction. When evaluating the degree of temporal bone pneumatization, we monitored the extension of mastoid cells (in each axial section) in relation to the 3 parallel reference lines of the sigmoid 

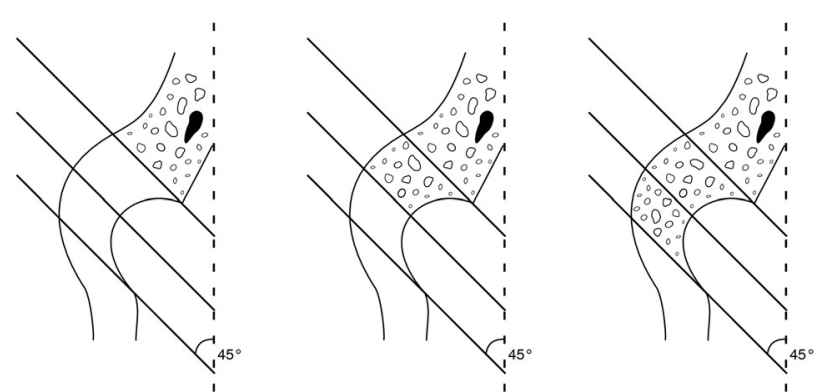

HYPOPNEUMATIZATION MODERATE PNEUMATIZATION GOOD PNEUMATIZATION

FIG 3. Degrees of mastoid pneumatization according to the descriptions of Han et al. ${ }^{6}$

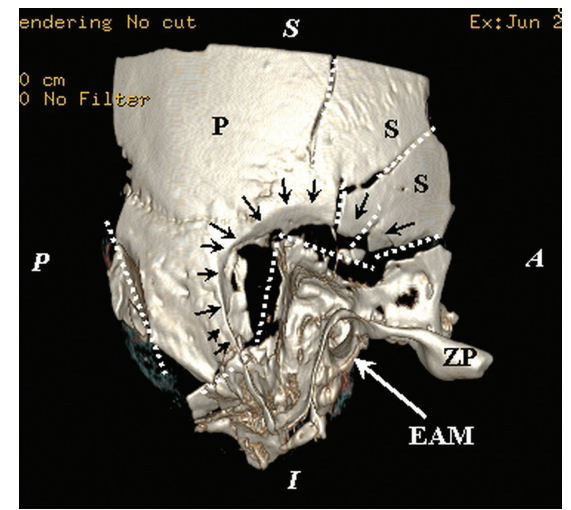

FIG 4. Temporal squama comminuted fracture: $3 D$ reconstruction of the exocranial surface of the right temporal bone of sample S1 with a volume-rendering technique. Comminuted fracture of the mastoid with extension in the petrous bone and important depression. In the center of the image is highlighted the aspect of bone depression (black arrows) that keeps the ball contour impaction at the junction with the mastoid and temporal scales; the main fracture lines are marked by dashed white lines. The sample position is indicated by marginal marks with white letters: S indicates superior; I, inferior; A, anterior; and P, posterior; black letter marks: ZP, zygomatic process of the temporal bone; $\mathrm{P}$, parietal portion; $\mathrm{S}$, scaly portion of the temporal bone. EAM, the external acoustic meatus, is indicated by the white arrow.

sinus according to the study performed by Han et $\mathrm{al}^{6}$ : through the anterior margin, through the maximal concavity opened medially, and through the posterior margin of the sigmoid sulcus. The lines maintained a $45^{\circ}$ inclination in relation to the anteroposterior axis of the image. Han et $\mathrm{al}^{6}$ showed that the degree of pneumatization of the entire mastoid can be estimated by evaluating the mastoid cells around the sigmoid sinus (Fig 3). Group I, with reduced pneumatization (hypopneumatization), is represented by mastoid cells positioned anteromedial to the most anterior line; group II, with moderate pneumatization, is represented by pneumatized cells extending between the first and second lines; group III, with good pneumatization, is represented by pneumatized cells between the middle and the last lines; and group IV, with hyperpneumatization, is represented by pneumatic cells situated posterolaterally to the last line. ${ }^{6}$

\section{Statistical Data Processing}

We used the following statistical tests: the Kolmogorov-Smirnov test for normal distribution and the Student $t$ test for the compar-

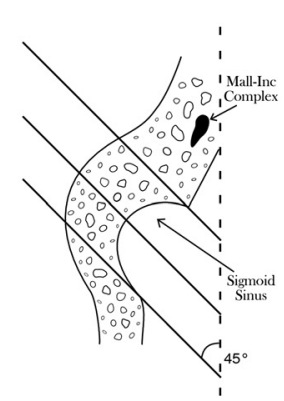

HYPERPNEUMATIZATION ison of the means in the case of 2 independent samples if the probability distribution was normal. If variables did not have a normal distribution, the Mann-Whitney test was used for the comparison of the ranks. The $\chi^{2}$ test or the Fisher exact test was used in case of qualitative variables. For the linear relationship between 2 discrete quantitative variables, the Pearson correlation coefficient was used, and for the nonlinear relationship between 2 discrete quantitative variables, the Spearman correlation coefficient was used. The significance threshold for the tests used was $\alpha=$ .05. Statistical calculations were performed by using the Statistical Package for the Social Sciences, Version 15.0 (IBM, Armonk, New York) and Excel applications (Microsoft, Redmond, Washington).

\section{RESULTS}

\section{Temporal Squama Fractures}

All temporal bone samples (M1-M10 and S1-S10) had temporal squama fractures (Fig 4). In the study group, horizontal, vertical, and oblique temporal squama fractures were present. In this group, horizontal and oblique fractures were predominant in equal proportions (36.53\% horizontal fractures, $36.53 \%$ oblique fractures, $26.92 \%$ vertical fractures), and comminuted fractures represented $42.85 \%$ of all fractures. In the control group, there were also horizontal, vertical, and oblique fractures. Horizontal fractures were predominant, followed by oblique fractures (44.44\% horizontal, $38.88 \%$ oblique, $16.66 \%$ vertical), and comminuted fractures represented $6.25 \%$ of all fractures. The number of temporal squama fracture lines was 2.88 times higher in the study group compared with the control group, and comminuted fractures were 12 times more frequent in the study group. Statistically significant differences were obtained between the 2 groups for horizontal $(P=.007)$ and vertical fractures $(P=.03)$.

\section{Mastoid Fractures}

All temporal bone samples (M1-M10 and S1-S10) had mastoid fractures. In both groups, horizontal, vertical, and oblique mastoid fractures were present. In both groups, oblique mastoid fractures were predominant, followed by horizontal fractures. In the study group, mastoid fractures were 2.76 times more frequent and comminuted fractures were 7 times more frequent compared with the control group. Statistically significant differences were obtained between the 2 groups for horizontal fractures $(P=.03)$ and oblique fractures $(P=.001)$.

\section{Temporal Bone Fractures with the Involvement of the Facial Nerve Canal}

The facial nerve canal was affected by fractures in $10 \%$ of the samples of the control group in the mastoid portion, compared with $60 \%$ in the study group. In the study group, facial nerve canal fractures were most frequently found in the mastoid portion (50\%), followed by the tympanic area (20\%) and the geniculate 

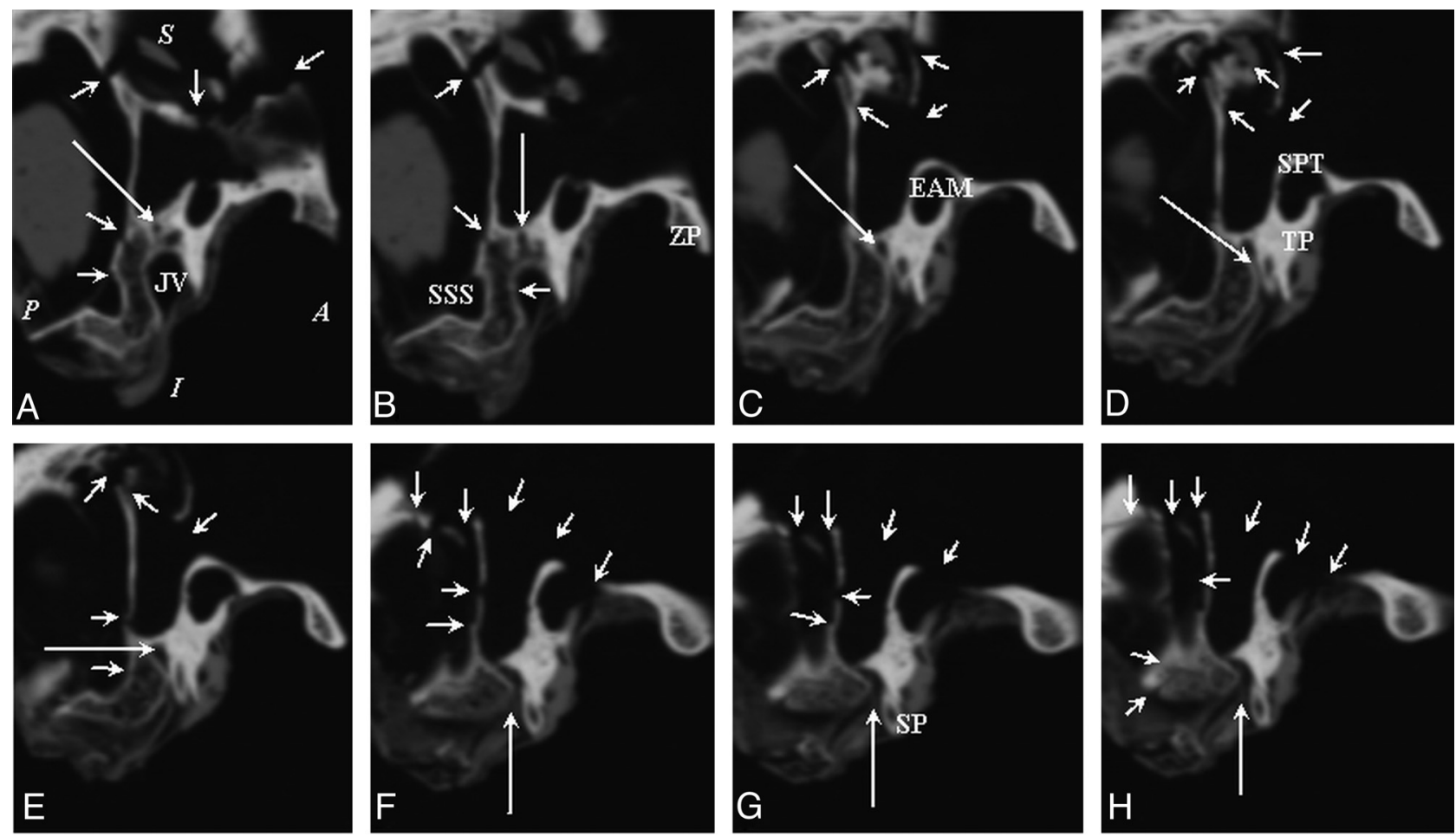

FIG 5. CT image of the mastoid segment of the facial nerve of sample $\mathrm{SI}(A-H)$ : successive $C T$ sections reconstructed in the sagittal plane in the distal segment of the mastoid canal up to the stylomastoid foramen. In the first image $(A)$, the position of the sample in the sagittal section is marked as follows: $A$ indicates anterior; $P$, posterior; $S$, superior; $I$, inferior. The fracture lines are marked by short arrows; the facial nerve canal is marked by a long arrow. $A$, JV, jugular vein. $B$, SSS, sigmoid sinus sulcus; ZP, zygomatic process. C, EAM, external auditory meatus. $D$ and $E$, The long arrow marks the descending segment of the facial nerve. D, TP, tympanic portion; SPT, squamous portion of the temporal bone (it forms the roof and the posterosuperior wall of the external auditory meatus). $F-H$, The long arrow indicates the stylomastoid foramen. $G$, SP, styloid process.

ganglion area (20\%); in 10\%, the internal auditory canal was affected (Fig 5).

\section{Fractures of Temporal Bone Foramina and Canals}

Fractures involving the carotid canal were found in $30 \%$ of the samples of the control group and in $70 \%$ of those of the study group. The stylomastoid foramen was affected by the fracture line in only 1 sample in the control group. The jugular foramen was affected in $20 \%$ of the samples of the control group and in $50 \%$ of the samples of the study group. The sigmoid sulcus was affected in $80 \%$ of the samples in the control group and $100 \%$ in the study group. These fractures can be seen in Fig 6 .

\section{Petrous and Nonpetrous Temporal Bone Fractures}

Temporal bone fractures, summarized according to the Ishman and Friedland ${ }^{9}$ classification (as petrous and nonpetrous), are shown in Table 1. The number of petrous fractures was 5.75 times more frequent in the study group than in the control group. The number of nonpetrous fractures was 3.18 times more frequent in the study group compared with the control group. In both groups, nonpetrous fractures were more frequent than petrous fractures.

\section{Mastoid Pneumatization}

In the control group, pneumatization type III was present in $30 \%$ of the samples, and pneumatization type IV, in $70 \%$ of the samples (Fig 7). Pneumatization types I and II, or sclerotic mastoids were not found in the control group. The samples with pneumati- zation type IV of the control group had more fracture lines with a higher severity than the samples with pneumatization type III, as can be seen in Table 2. By relating the number of fracture lines to the number of samples, one can see that the samples in the control group with pneumatization type IV had 1.8 times more fracture lines than the samples with pneumatization type III of the same group.

In the study group, pneumatization type IV was present in $30 \%$ of the samples. In the other temporal bone samples of this group, the degree of pneumatization could not be evaluated because multiple fragments were partially destroyed after impaction.

\section{DISCUSSION}

This study demonstrates that mastoid pneumatization and architecture play a role in the mechanical protection of the temporal bone structures during direct lateral trauma. The mastoid plays the role of absorbing and dispersing impacting kinetic energy. Trauma was applied to the temporal bone samples by using a weight with a radius of $60 \mathrm{~mm}$. Rhee et $\mathrm{al}^{10}$ showed, in a study on the biomechanics of zygomatic bone fractures on cadaver heads, that the severity of the fractures did not depend on the contact surface area or on the thickness of the soft tissue covering the bone. They showed that the impacting speed was best correlated with the severity of the fractures and its threshold was $3.5 \mathrm{~m} / \mathrm{s}$. In our study, the mean impacting speed of the temporal bone samples was $3.35 \pm 0.013 \mathrm{~m} / \mathrm{s}$ with an isolated and formalinized temporal bone. 
By removing, in the study group, the external cortex of the mastoids and mastoid cells, a low-resistance area was created. In the study group, the fracture lines were, in fact, fracture surfaces
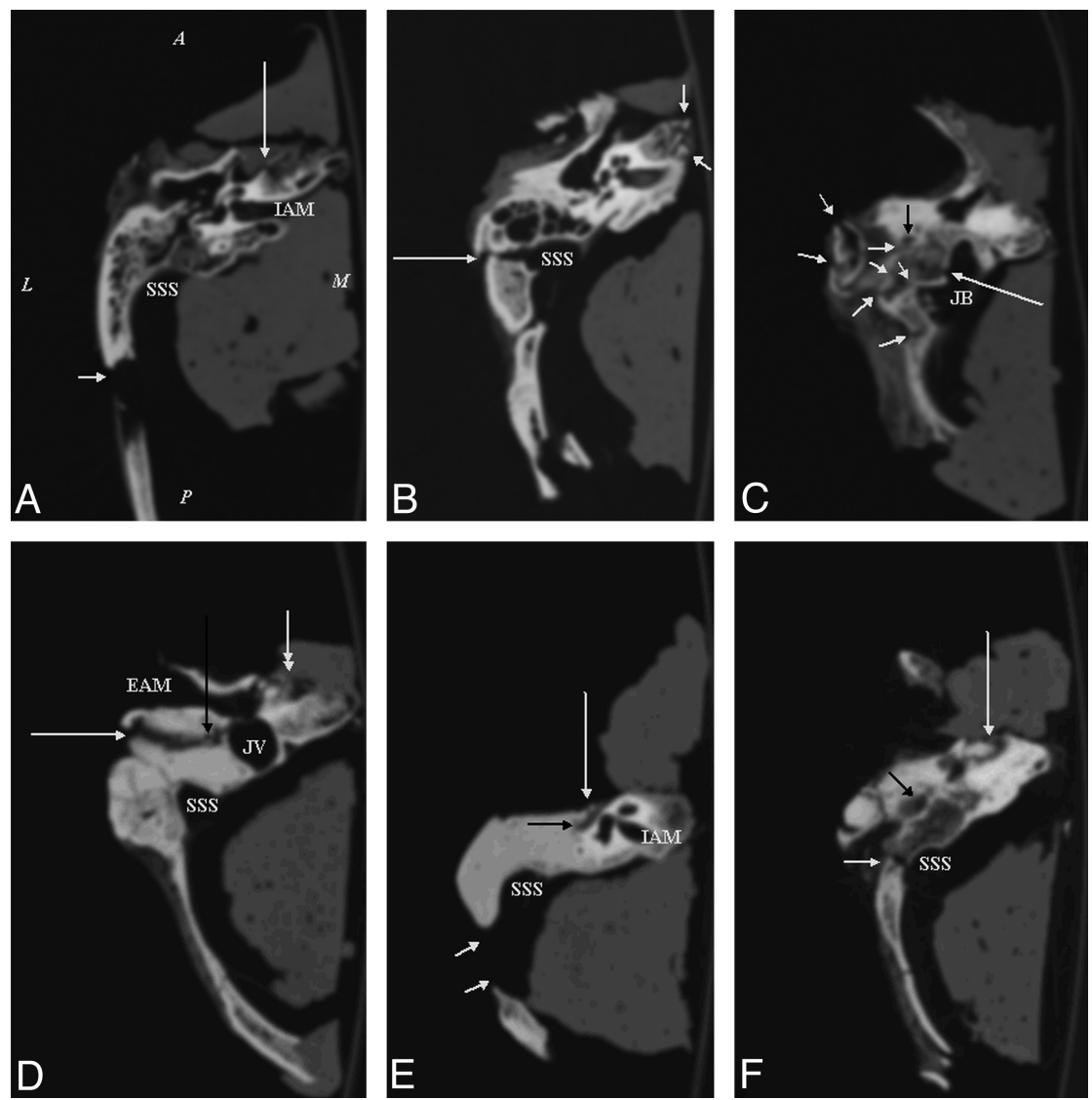

FIG 6. Axial CT sections involving vital structures of the temporal bone. The first images $(A-C)$ belong to the control group, and the last images $(D-F)$ belong to the study group. The position of the samples in the axial plane is marked as follows: $A$ indicates anterior; $P$, posterior; $L$, lateral; $M$, medial on the first image. Short white arrows indicate fracture lines with different orientations in different parts of the temporal bone. Long white arrows indicate fractures of walls of vascular and nerve structures: carotid canal in images $A$ and $D$ (double-tipped arrow), and $F$; sigmoid sinus sulcus and jugular vein bulb in images $B$ and $C$; the mastoid segment of facial nerve in the image $D$; the tympanic segment of the facial nerve in the image $E$; the stylomastoid foramen in the image $F$. The black arrows indicate the different portions of the facial nerve: the mastoid portion in $C$ and $D$, tympanic in $E$, and the stylomastoid foramen in $F$. IAM indicates internal auditory meatus; SSS, sigmoid sinus sulcus; JB, jugular bulb; JV, jugular vein; EAM, external auditory meatus. A, M3 sample section at the level of the internal auditory meatus. The long white arrow indicates a fracture line at the medial wall of the carotid canal. B, M4 sample section at the level of epitympanic portion. The long white arrow indicates a longitudinal fracture line at the lateral wall of the sigmoid sulcus. The short white arrows indicate a comminuted fracture of the petrous apex. $C$, M8 sample section at the level of the jugular bulb: The long white arrow indicates a longitudinal fracture line at the lateral wall of the jugular bulb sulcus. The short white arrows indicate a comminuted fracture of the mastoid. D, S4 sample section at the level of the external auditory meatus. The long white arrow indicates a longitudinal fracture line involving the mastoid segment of the facial nerve; the white double-tipped arrow indicates a comminuted fracture of the lateral wall of the carotid canal. E, S6 sample section at the level of the tympanic portion of the facial nerve. The long white arrow indicates a fracture line involving the facial nerve. $F$, S5 sample section at the level of the stylomastoid foramen. The long white arrow indicates a bone fragment in the roof of the carotid canal. brain tissue adjacent to the temporal bone would have been more severe in the study group.

The classic classification of temporal bone fractures (ie, transverse, longitudinal, and oblique) does not correlate with the clinical aspects of facial nerve dysfunction as well as the classification that categorizes fractures as petrous and nonpetrous. ${ }^{9}$ Ishman and Friedland ${ }^{9}$ showed that in petrous fractures, facial nerve lesions are 3 times more frequent and CSF leakage is 10 times more frequent. If fractures are nonpetrous and involve the mastoid portion of the facial nerve, facial nerve injuries are less likely to occur. ${ }^{9}$ In our study, in the control group, the facial nerve canal fracture was in the mastoid portion, which is part of the nonpetrous temporal bone fracture, thus with fewer chances to induce facial nerve lesions. In contrast, in the study group, petrous fractures were 5.75 times more frequent, with higher chances to induce facial nerve lesions, considering that facial nerve canal fractures were 6 times more frequent.

Carotid canal fractures were 2.33 times more frequent in the study group. York et $\mathrm{al}^{11}$ showed that carotid canal fractures had a $60 \%$ sensitivity and $67 \%$ specificity for the detection of internal carotid artery injuries in subjects with head trauma. In their study, the frequency of internal carotid injuries was twice as high in patients with carotid canal fractures as in those without carotid canal fractures. Internal carotid injuries were predominantly represented by dissection, and in 1 patient, by carotid cavernous fistula. ${ }^{11}$

The jugular foramen was affected by the fracture line 2.5 times more frequently in the study group, which increased the risk of sigmoid sinus thrombosis. Delgado Almandoz et $\mathrm{al}^{12}$ showed

Table 1: Petrous and nonpetrous temporal bone fractures in the control and study groups

\begin{tabular}{|c|c|c|c|c|c|c|}
\hline \multirow[b]{2}{*}{ Type of Fracture } & \multicolumn{3}{|c|}{ M1-M10 } & \multicolumn{3}{|c|}{ S1-S10 } \\
\hline & $\begin{array}{c}\text { Transverse } \\
\text { Fracture, No } \\
\text { Fracture Lines }\end{array}$ & $\begin{array}{l}\text { Longitudinal } \\
\text { Fracture, No } \\
\text { Fracture Lines }\end{array}$ & $\begin{array}{c}\text { Oblique } \\
\text { Fracture, No } \\
\text { Fracture Lines }\end{array}$ & $\begin{array}{c}\text { Transverse } \\
\text { Fracture, No } \\
\text { Fracture Lines }\end{array}$ & $\begin{array}{l}\text { Longitudinal } \\
\text { Fracture, No } \\
\text { Fracture Lines }\end{array}$ & $\begin{array}{c}\text { Oblique } \\
\text { Fracture No, } \\
\text { Fracture Lines }\end{array}$ \\
\hline Petrous fracture & 4 & 0 & 0 & 11 & 4 & 8 \\
\hline Non-petrous fracture & 5 & 8 & 9 & 23 & 18 & 29 \\
\hline
\end{tabular}


that patients with skull fractures in whom fractures were extended to the sigmoid sinus or/and jugular bulb had a $40.7 \%$ overall risk for thrombosis. They found a higher injury risk for the sigmoid sinus, transverse sinus, and jugular bulb in petrous temporal bone fractures. $^{12}$

Given that mastoid pneumatization could not be evaluated in all samples in the study group (because some pieces were destroyed) and the small number of samples in the 2 groups, a statistical study between the degree of mastoid pneumatization and
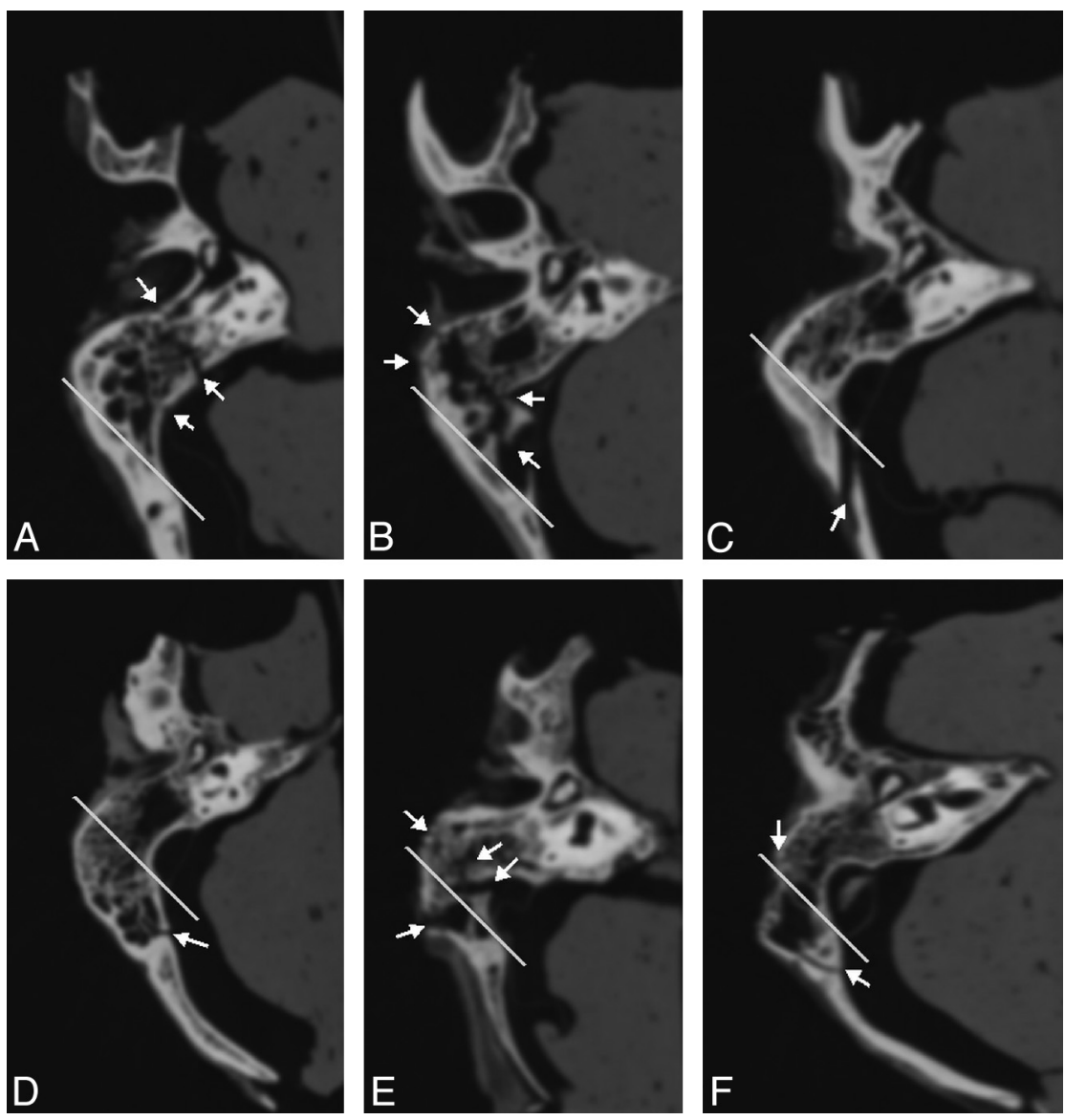

FIG 7. Axial $C T$ section at the level of the sigmoid sinus and epitympanum in samples $M 1(A), M 5$ $(B), M 6(C), M 7(D), M 8(E)$, and M10 $(F)$. The white line marks the separation between pneumatization degree III and IV. Samples from images $A-C$ show pneumatization degree III, and the images $D-F$ show pneumatization degree IV. Short white arrows mark the fracture lines highlighted in these sections.

Table 2: The degree of pneumatization and the type of fractures in the control group

\begin{tabular}{|c|c|c|c|c|c|c|c|}
\hline \multirow[b]{2}{*}{$\begin{array}{l}\text { Type of Fracture } \\
\text { Samples M1-M10 }\end{array}$} & \multirow[b]{2}{*}{$\begin{array}{c}\text { Pneumatization } \\
\text { Degree }\end{array}$} & \multicolumn{3}{|c|}{ Petrous Fracture } & \multicolumn{3}{|c|}{ Nonpetrous Fracture } \\
\hline & & $\begin{array}{c}\text { Transverse } \\
\text { Fracture, No } \\
\text { Fracture Lines }\end{array}$ & $\begin{array}{l}\text { Longitudinal } \\
\text { Fracture, No } \\
\text { Fracture Lines }\end{array}$ & $\begin{array}{c}\text { Oblique } \\
\text { Fracture, No } \\
\text { Fracture Lines }\end{array}$ & $\begin{array}{c}\text { Transverse } \\
\text { Fracture, No } \\
\text { Fracture Lines }\end{array}$ & $\begin{array}{l}\text { Longitudinal } \\
\text { Fracture, No } \\
\text { Fracture Lines }\end{array}$ & $\begin{array}{c}\text { Oblique } \\
\text { Fracture, No } \\
\text { Fracture Lines }\end{array}$ \\
\hline $\mathrm{Ml}$ & IV & 1 & - & - & 1 & - & 3 \\
\hline M2 & III & - & - & - & - & 1 & 1 \\
\hline M3 & IV & - & - & - & - & - & 1 \\
\hline M4 & IV & 1 & - & - & 1 & 1 & - \\
\hline M5 & IV & 1 & - & - & 3 & 1 & 1 \\
\hline M6 & III & - & - & - & - & 1 & - \\
\hline M7 & IV & - & - & - & - & 1 & - \\
\hline M8 & IV & - & - & - & - & 1 & 1 \\
\hline M9 & III & 1 & - & - & - & 1 & - \\
\hline M10 & IV & - & - & - & - & 1 & 2 \\
\hline
\end{tabular}

Note:- indicates no fracture lines. the severity of temporal bone fractures could not be performed. In the control group, however, samples with pneumatization type IV had more fracture lines than those with pneumatization type III. These results suggest that mastoids with hyperpneumatization have a higher susceptibility to fracture than mastoids with good pneumatization. By extrapolating the results obtained in the control group, it might be thought that a mastoid with a single large air cell would fracture more easily than one with the same air content but with bone septa. There might be an optimal ratio between the air volume of the mastoid and that of the bone walls of the mastoid air-cell system, which might provide the protection of vital structures in the temporal bone. Our study did not include acellular mastoids of developmental or secondary causes that could have provided additional information about the mechanical protection of the mastoid.

The limitations of the study are the small number of samples included. In addition, the study was not performed on fresh temporal bone samples, but on formalinized samples. The formalin used for conservation determined the dehydration of the samples and changes of bone structure proteins. All these aspects alter bone elasticity and the susceptibility of bone tissue to fracture.

\section{CONCLUSIONS}

In the setting of lateral trauma, mastoid architecture with air spaces appears to contribute to the absorption and dispersion of impacting kinetic energy and to the protection of vital structures in the temporal bone.

\section{ACKNOWLEDGMENTS}

The authors thank Remus Văidăhăzan for the beautiful illustration of the degrees of mastoid pneumatization. 
Disclosures: Aranka llea-RELATED: Grant: Sectorial Operational Programme for Human Resources Development (POSDRU) project 88/1.5/S/78702.* Lucia Hurubeanu-UNRELATED: Grants/Grants Pending: New Biocompatible Materials for Personalized Implants Made by Selective Laser Sintering and Selective Laser Melting (BIOMAPIM); Project CNCSIS (National Council of Scientific Research in Higher Education), PN-II-ID-PCCE-2008-1 (PN, National Plan; ID, Ideas; PCCE, Exploratory Complex Research Projects). * Money paid to the institution.

\section{REFERENCES}

1. Kellman RM, Schmidt C. The paranasal sinuses as a protective crumple zone for the orbit. Laryngoscope. 2009;119:1682-90

2. Hill CA, Richtsmeier JT. A quantitative method for the evaluation of three-dimensional structure of temporal bone pneumatization. $J$ Hum Evol 2008;55:682-90

3. Virapongse C, Sarwar M, Bhimani S, et al. Computed tomography of temporal bone pneumatization: normal pattern and morphology. AJR Am J Roentgenol 1985;145:473-81

4. Sadé J, Ar A. Middle ear and auditory tube: middle ear clearance, gas exchange, and pressure regulation. Otolaryngol Head Neck Surg 1997;116:499-524

5. Sadé J, Fuchs C. Secretory otitis media in adults: I. The role of mastoid pneumatization as a risk factor. Ann Otol Rhinol Laryngol 1996;105:643-47
6. Han SJ, Song MH, Kim J, et al. Classification of temporal bone pneumatization based on sigmoid sinus using computed tomography. Clin Radiol 2007;62:1110-08

7. Valtonen HJ, Dietz A, Qvarnberg YH, et al. Development of mastoid air cell system in children treated with ventilation tubes for earlyonset otitis media: a prospective radiographic 5-year follow-up study. Laryngoscope 2005;115:268-73

8. Turgut S, Tos M. Correlation between temporal bone pneumatization, location of lateral sinus and length of the mastoid process. $J$ Laryngol Otol 1992;106:485-89

9. Ishman SL, Friedland DR. Temporal bone fractures: traditional classification and clinical relevance. Laryngoscope 2004;114:1734-41

10. Rhee JS, Posey L, Yoganandan N, et al. Experimental trauma to the malar eminence: fracture biomechanics and injury patterns. Otolaryngol Head Neck Surg 2001;125:351-55

11. York G, Barboriak D, Petrella J, et al. Association of internal carotid artery injury with carotid canal fractures in patients with head trauma. AJR Am J Roentgenol 2005; 184:1672-78

12. Delgado Almandoz JE, Kelly HR, Schaefer PW, et al. Prevalence of traumatic dural venous sinus thrombosis in high-risk acute blunt head trauma patients evaluated with multidetector CT venography. Radiology 2010;255:570-77 